\title{
Peningkatan Hasil Belajar Matematika Melalui Model Problem Based Learning Kelas 1 SDN Krasak 01
}

\author{
Ita Rosita \\ SDN Krasak 01 Brebes \\ ita35292@gmail.com
}

\section{Article History}

received 3/12/2020

\begin{abstract}
This study aims to determine the improvement of students' learning outcomes through problem based learning methods. The subjects in this study were grade 1 sdn Krasak 01 which consisted of 15 girls 5 boys. Kkm standard 65 out of 20 children only 7 students or $45.5 \%$ who reached a value of 65 and above while 13 students or $54.5 \%$ got a score below KKM. The results showed that the improvement of students' learning outcomes through problem based learning model. In pre-cycles obtained an average score of $61.5 \%$ then increased in cycle 1 with a score of $65 \%$, increased back in the second cycle $69 \%$. From the results of the research, it can be concluded that the problem based learning model can improve the students of SDN Krasak 01.
\end{abstract}

Keywords: learning outcomes, problem based learning

\begin{abstract}
Abstrak
Penelitian ini bertujuan untuk mengetahui peningkatan hasil belajar siswa melalui metode problem based learning.Subjek dalam penelitian ini adalah kelas 1 SDN Krasak 01 yang berjumlah 20 yang terdiri dari 15 anak perempuan 5 anak laki-laki.Standar KKM 65 dari 20 anak hanya 7 peserta didik atau $45,5 \%$ yang mencapai nilai 65 keatas sedangkan 13 peserta didik atau $54,5 \%$ mendapat nilai dibawah KKM. Hasil penelitian menunjukkan bahwa peningkatan hasil belajar siswa melalui model problem based learning. Pada pra siklus memperoleh nilai rata-rata $61.5 \%$ kemudian mengalami peningkatan pada siklus 1 dengan skor $65 \%$,meningkat kembali pada siklus yang kedua $69 \%$. Dari hasil penelitian dapat disimpulkan bahwa model problem based learning dapat meningkatkan siswa SDN Krasak 01.
\end{abstract}

Kata kunci: hasil belajar, problem based learning

Social, Humanities, and Education Studies (SHEs): Conference Series https://jurnal.uns.ac.id/shes 


\section{PENDAHULUAN}

indikator pendidikan yang berkualitas khususnya di SDN Krasak 01 dapat dilihat dari perolehan nilai hasil belajar. Nilai hasil belajar peserta didik dapat ditingkatkan apabila pembelajaran berlangsung secara efektif dan efesien yang ditunjang oleh tersedianya sarana dan prasarana yang mendukung serta kelengkapan guru dalam perangkat yang digunakan. Keberhasilan proses pembelajaran yang dilakukan guru dalam kelas seharusnya menggunakan model pembelajaran sehingga meningkatkan ketrampilan peserta didik dalam berpikir tingkat tinggi yang berpengaruh pada hasil belajar peserta didik.

Berdasarkan studi pendahuluan yang dilakukan oleh peneliti di SDN Krasak 01 menemukan beberapa masalah yang berkaitan dengan pembelajaran terutama pada muatan pelajaran matematika dikarenakan pembelajaran berpusat pada guru model yang digunakan konvensional yang berdampak pada rendahnya hasil belajar peserta didik. Untuk memecahkan masalah tersebut dengan menerapkan model pembelajaran problem based learning dengan melibatkan kemampuan berpikir peserta didik untuk memecahkan masalah menyelidiki secara sistematis,logisdan kritis.

Penelitian serupa diakukan dari jurnal pendidikan matematika Arini Mayang Fauni Satya Wacana christian university. Hasil penelitian menunjukkan bahwa terdapat peningkatan nilai Matematika yang signifikan. Peningkatan tersebut terlihat dari indikatornya sebagai berikut: 1) siswa antusias bertanya sebelum tindakan 10,34\%, siklus I 20,68\%, dan siklus II 34,48\%, 2) siswa antusias menjawab pertanyaan. tanya jawab sebelum tindakan $13,79 \%$, siklus I $27,59 \%$, dan siklus II $55,17 \%$, 3) siswa bersemangat mengerjakan soal di depan kelas sebelum tindakan $17,24 \%$, siklus I 34 , $48 \%$, dan siklus II 65,52\%. Peningkatan nilai Matematika siswa terlihat dari nilai yang dicapai KKM sebelum tindakan 20,68\%, siklus I 44,82\%, dan siklus II $89,65 \%$. Berdasarkan uraian di atas, dapat disimpulkan bahwa implikasi Problem Based Learning dengan Strategi Card Sort dalam pembelajaran Matematika dapat meningkatkan nilai Matematika.

Dari penelitian tersebut hasil belajar peserta didik meningkat,dari analisa SDN Krasak 01 peneliti memiliki solusi yang tepat untuk memecahkan masalah tentang rendahnya hasil belajar peserta didik dengan menerapkan model problem based learning. Berdasarkan identifikasi masalah yang diungkapkan diatas maka peneliti melakukan penelitian dengan judul peningkatan hasil belajar matematika melalui model problem based learning.

\section{METODE}

Jenis penelitian dimana digunakan adalah penelitian tindakan kelas (action research). Penelitian dilakukan di SDN Krasak 01 Kecamatan Brebes, kabupaten Brebes, Propinsi Jawa Tengah pada semester ganjil bulan Juli-Agustus,subjek pada penelitian ini adalah 20 peserta didik kelas 1 SDN Krasak 01 Brebes. Peneliti melaksanakan penelitian dua siklus,setiap siklus dengan 2 kali pertemuan adapun prosedur yang dilakukan pada penelitian tindakan kelas yaitu: 1) refleksi awal, 2) menyusun perencanaan, 3) pelaksanaan tindakan, 4) observasi, 5) refleksi.

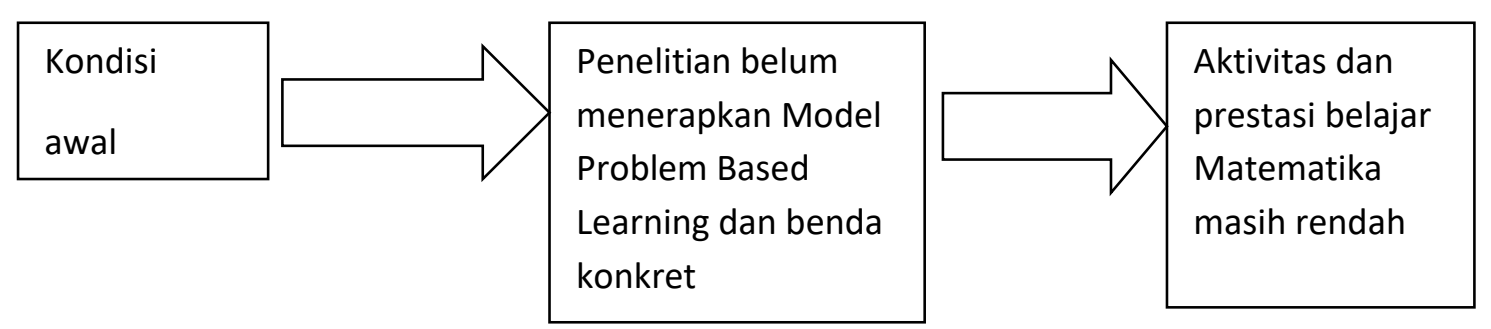




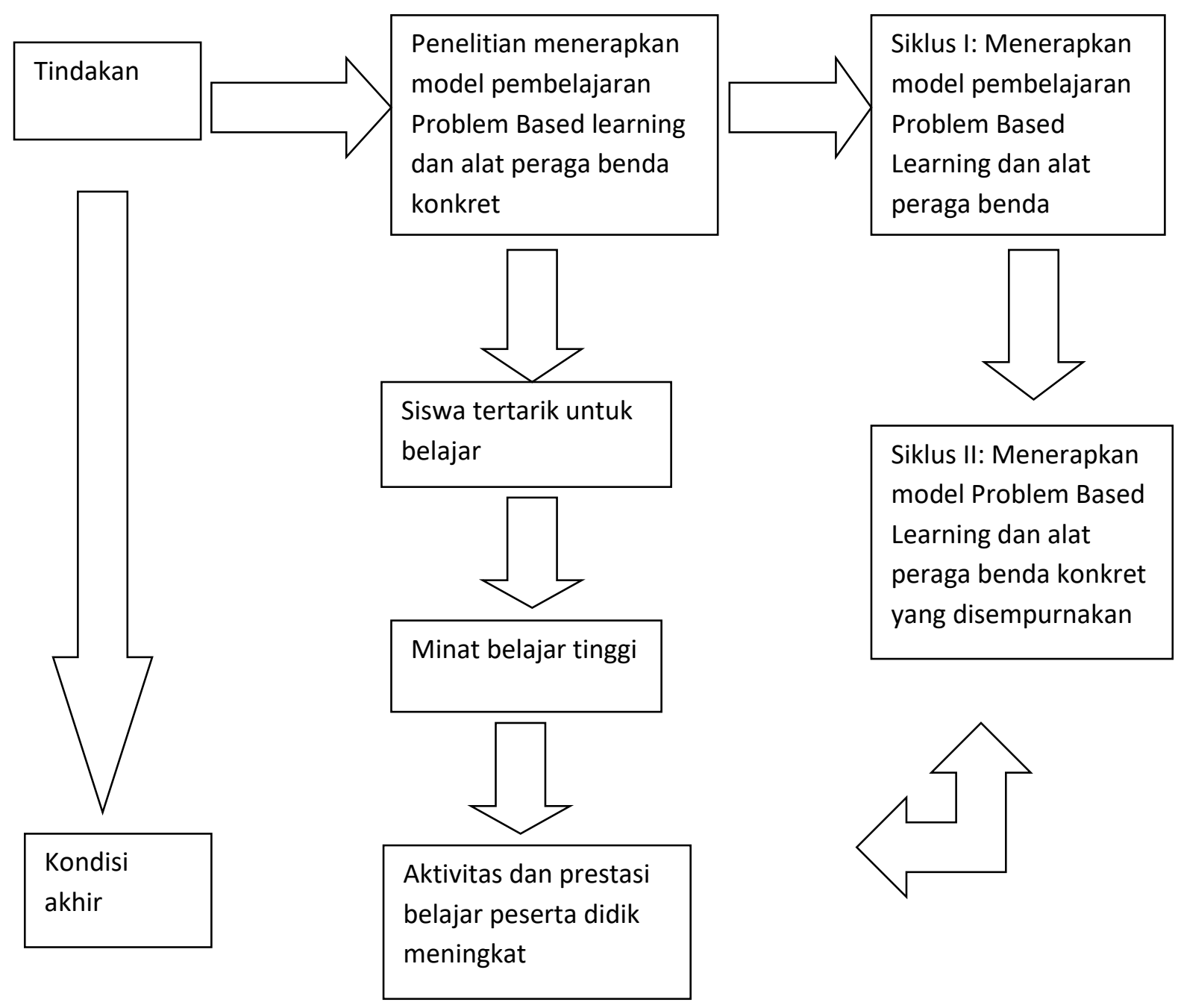

Berdasarkan kerangka berpikir diatas, maka hipotesis tindakan penelitian ini adalah :

1. Dengan menggunakan model Problem Based Learning dan alat peraga benda konkret dapat meningkatkan kompetensi belajar mata pelajaran Matematika tentang mengurutkan bilangan pada peserta didik kelas 1 SDN Krasak 01 Semester 1 Tahun pelajaran 2021/2022 Kecamatan Brebes Kabupaten Brebes.

2. Dengan menggunakan model Problem Based Learning dan alat peraga benda konkret dapat meningkatkan aktivitas belajar mata pelajaran Matematika tentang mengurutkan bilangan pada peserta didik kelas 1 SDN Krasak 01 Semester 1 Tahun pelajaran 2021/2022 kecamatan Brebes Kabupaten Brebes. 


\section{HASIL DAN PEMBAHASAN}

A. Deskripsi hasil penelitian tindakan kelas perbaikan pembelajaran

Penulis telah melakukan penelitian tindakan kelas sebanyak dua siklus. Selanjutnya disampaikan hasil perbaikan pada masing-masing siklus akan mencakup penilaian perbaikan dan hasil belajar peserta didik.

1. Pra siklus

a. Hasil pengolahan data

Berikut ini kami sajikan data kualitas pelaksanaan aktivitas penelitian tindakan kelas Matematika dikelas 1 SDN Krasak 01 sebelum perbaikan.

Data hasil belajar peserta didik dalam pembelajaran Matematika Pra siklus

Tabel 1. Data Hasil Belajar peserta didik dalam pembelajaran Matematika Pra siklus

\begin{tabular}{ccc}
\hline $\begin{array}{c}\text { Skala Nilai } \\
(\mathbf{1 0 - 1 0 0 )}\end{array}$ & Jumlah Siswa & Jumlah nilai \\
\hline 100 & 0 & 0 \\
90 & 0 & 0 \\
80 & 5 & 400 \\
70 & 2 & 140 \\
60 & 6 & 360 \\
50 & 5 & 250 \\
40 & 2 & 80 \\
30 & 0 & 0 \\
Jumlah & 20 & 1230 \\
Nilai rata-rata & & 61,5 \\
\hline
\end{tabular}

Setelah dilakukan analisis dan refleksi terhadap perolehan hasil pelaksanaan pembelajaran pra siklus diketahui masih terdapat kelemahan-kelemahan antara lain:

1) Guru masih lupa menyampaikan tujuan pembelajaran yang telah direncanakan pada awal pembelajaran.

2) Pertanyaan masih berpusat pada beberapa peserta didik saja.

3) Guru belum memberi motivasi.

4) Siswa belum aktif dalam pembelajaran.

2. Siklus 1

5) Nilai formatif peserta didik mencapai rata-rata. baik.

Secara umum dapat dikatakan bahwa pelaksanaan pembelajaran berjalan dengan

Tabel 2. Data kualitas pelaksanaan aktivitas penelitian tindakan kelas Matematika siklus 1

\begin{tabular}{ccc}
\hline $\begin{array}{c}\text { Skala Nilai } \\
(\mathbf{1 0 - 1 0 0 )}\end{array}$ & $\begin{array}{c}\text { Jumlah Skor peserta } \\
\text { didik }\end{array}$ & Jumlah Nilai \\
\hline 100 & 0 & 0 \\
90 & 1 & 90 \\
80 & 5 & 400 \\
70 & 4 & 280 \\
60 & 5 & 300 \\
50 & 3 & 150 \\
40 & 2 & 80 \\
30 & 0 & 0 \\
Jumlah & 20 & 1300 \\
Nilai rata-rata & & 65,00 \\
\hline
\end{tabular}


Dari data di atas dapat dilihat adanya kenaikan yang cukup signifikan terhadap hasil pembelajaran yan didapat. Setelah dilakukan analisis dan refleksi terhadap perolehan hasil perbaikan pada siklus pertama diketahui masih terdapat kelemahankelemahan antara lain:

1) Guru masih lupa menyampaikan tujuan pembelajaran yang telah direncanakan akan disampaikan pada awal pembelajaran.

2) Pertanyaan masih berpusat pada peserta didik yang pintar saja.

3) Guru belum memberi penguatan pada peserta didik.

4) Guru belum memberikan bimbingan yang terarah pada peserta didik dalam melakukan diskusi kelompok.

5) Nilai formatif peserta didik mencapai rata-rata 70,5

3. Siklus 2

Setelah melakukan refleksi pada siklus 1 sekarang akan dilanjutkan pada siklus 2 , Hal ini dilakukan agar mengetahui sejauh mana penerapan pembelajaran problem Based learning tidak hanya meningkatkan tetapi juga mempertahankan hasil belajar peserta didik.

Tabel 3. Data hasil belajar peserta didik dalam pembelajaran Matematika siklus 2

\begin{tabular}{lll}
\hline $\begin{array}{l}\text { Skala Nilai } \\
(\mathbf{1 0 - 1 0 0 )}\end{array}$ & Jumlah Siswa & Jumlah Nilai \\
\hline 100 & 1 & 100 \\
90 & 1 & 90 \\
80 & 4 & 320 \\
70 & 6 & 420 \\
60 & 5 & 300 \\
50 & 3 & 150 \\
40 & 0 & 0 \\
30 & 0 & 0 \\
Jumlah & 20 & 1.380 \\
Nilai rata-rata & & 69,00 \\
\hline
\end{tabular}

B. Pembahasan Hasil Penelitian tindakan kelas perbaikan pembelajaran

Dari data kualitas pelaksanaan penelitian tindakan kelas dan hasil tes formatif peserta didik di kelas 1 SDN Krasak 01 Brebes dapat dikatakan bahwa pelaksanaan penelitian tindakan kelas rata-rata meningkat .

Peningkatan prestasi belajar peserta didik terjadi karena dalam penelitian tindakan kelas secara konsekuen penulis melakukan aktivitas-aktivitas pembelajaran yang meliputi:

1) Keaktifan peserta didik dalam tanya jawab

Tanya jawab adalah cara penyajian pelajaran dalam bentuk pertanyaan yang harus dijawab terutama dari guru kepada siswa tetapi dapat pula dari siswa kepada guru.

2) Pemberian penjelasan

Cara guru dalam usaha untuk menyampaikan pengetahuan dan informasi kepada peserta didik yang mudah dipahami dan dimengerti dengan jelas oleh semua peserta didik.

3) Pemanfaatan media pembelajaran

Media pembelajaran merupakan salah satu jalan untuk memudahkan seorang guru dalam melaksanakan tugasnya untuk mencapai tujuan pembelajaran.

4) Pengaktifan peserta didik dalam latihan soal

Pemberian latihan soal-soal dimaksudkan memberikan kesempatan pada peserta didik untuk melaksanakan tugas dan mengukur kemampuan peserta didik. 
5) Pemberian soal evaluasi

Dalam proses belajar mengajar yang melakukan evaluasi adalah guru yang merencanakan dan melaksanakan kegiatan belajar mengajar. Guru sebagai sumber informasi yang selalu berinteraksi dengan anak didik memerlukan evaluasi secara teratur agar dapat memperbaiki atau menyempurnakan proses belajar mengajar.

Tujuan evaluasi adalah memberi informasi yang berkaitan dengan kemampuan peserta didik,pembinaan kegiatan belajar,menerapkan kemampuan dalam kesulitan,mendorong motivasi belajar.

Hasil pelaksanan penelitian tindakan kelas pada siklus kedua ini sudah maksimal. Setelah dilihat dari analisis ternyata menunjukkan adanya peningkatan kualitas belajar. Dengan pemberian motivasi dan pemanfaatan metode pembelajaran secara maksimal dan pemberian pengarahan sebelum pelaksanaan pembelajaran. Hal ini dapat dilihat dari setiap nilai rata-rata kelas peserta didik dalam mengerjakan soal tes akhir jika dibandingkan dari hasil pra siklus dan siklus pertama.

Pada prasiklus nilai rata-rat kelasnya 61,5 atau hanya 7 peserta didik dari 20 peserta didik telah tuntas atau sekitar $35 \%$ berhasil, pada siklus 1 nilai rata-rata kelasnya 65 sejumlah 10 peserta didik yang tuntas dari 20 peserta didik sekitar $50 \%$ telah berhasil,sedangkan pada siklus 2 nilai rata-rata kelasnya 69 atau 12 peserta didik telah tuntas dari 20 peserta didik sekita $60 \%$ telah berhasil.

\section{SIMPULAN}

Ada beberapa kesimpulan yang dapat diambil dari kegiatan penelitian tindakan kelas yang sudah dilaksanakan,kesimpulan tersebut adalah :

1. Penerapan metode Problem Based Learning dapat meningkatkan prestasi belajar peserta didik. Hal ini dapat dilihat dari skor hasil tes peserta didik yang meningkat setiap siklusnya. Skor prestasi belajar peserta didik pada siklus 50\% meningkat menjadi $60 \%$ pada siklus 2 .

2. Penerapan metode Problem Based Learning dapat meningkatkan kualitas peserta didik. Hal tersebut dapat dilihat dari hasil evaluasi belajar peserta didik meningkat siklus demi siklus. Rata-rata kelas meningkat dari prasiklus $35 \%$ meningkat menjadi $50 \%$ pada siklus 1 dan siklus 2 naik menjadi $60 \%$.Begitu pula nilai terendah peserta didik yaitu 40 dan 90 pada prasiklus menjadi 50 dan 100 pada siklus 2 .

\section{DAFTAR PUSTAKA}

Andayani; dkk. (2007). Pemantapan Kemampuan Profesional. Jakarta: Univeritas Terbuka

Arikunto, Suharsimi. 2010. Penelitian Tindakan Kelas. Jakarta:Bumi aksara.

Amir, Taufiq. 2009. Inovasi Pendidikan Melalui problem Based Learning. Jakarta: kencana.

Aqib, zainal. 2011. Penelitian Tindakan Kelas. Bandung: Yrama Widya.

Dahar,Ratna wilis.2011.Teori Belajar dan Pembelajaran. Jakarta:Erlangga.

Departemen Pendidikan Nasional. 2006. Kurikulum Tingkat Satuan Pendidikan. Jakarta:Depdiknas.

Departemen Pendidikan Nasional. (2006). Peraturan Menteri Nasional RI No.22,23,24. Jakarta.

Depdikbud (1986). Pedoman Proses Belajar Mengajar. Jakarta: Depdikbud

Karim, Muchtar, A; dkk (2004).Pendidikan Matematika I. Jakarta : Pusat penerbitan universitas terbuka 